\title{
De la ciudad negada a la ciudad anhelada. Análisis del proyecto institucional de rescate a espacios públicos en México
}

\author{
From the denied City to the desired City \\ Analysis of the institutional project of rescue to public spaces \\ in Mexico
}

Carlos Alberto Crespo Sánchez*

Citar este artículo como: Crespo Sánchez, C. A. (2019). De la ciudad negada a la ciudad anhelada. Análisis del proyecto institucional de rescate a espacios públicos en México. Revista Nodo, 13(26), pp. 30-41

\section{Resumen}

Orden espacial y fortalecimiento de lazos comunitarios, valores que se pronuncian como principal anhelo y objetivo alcanzable que da sustento a los actuales esfuerzos por rescatar al espacio público en México, y a partir de los cuales, se definen no solo las características que instituyen a la ciudad y el espacio público anhelado, sino también, los parámetros para catalogar los espacios en situación de abandono, desarticulación, y, por tanto, inhabilitados para la generación de valores ciudadanos compartidos, un espacio erradicable. El presente artículo analiza el Programa de Rescate a Espacios Públicos con el fin de determinar la estructura ideológica y los mecanismos legitimadores que subyacen a los planteamientos que determinan la relación entre la ciudad negada y la ciudad anhelada.

Palabras clave: Espacio público, rescate, orden, institución, ideología.

\section{Abstract}

Spatial order and strengthening of community bonds, values that are pronounced as the main and achievable goal that sustains the actual efforts to rescue the public space in Mexico, and from which, are defined, not only the characteristics that institute the City and the desired Public space, but also, the parameters to catalog the spaces in abandon situations, dislocation, and, so, disabled to generate citizen shared values, an eradicable space. The present article analyzes the Rescue of Public Spaces Program to determine the Ideological Structure and the legitimate mechanisms that underlie the exposure of what determines the relationship between the denied City and the desired City.

Key words: Public Space, Rescue, Order, Institution, Ideology

\section{Fecha de recepción: 17 de febrero de 2019 • Fecha de aceptación: 1 de abril de 2019}

\footnotetext{
* Doctor en Ciudad, Territorio y Sustentabilidad. Investigador asociado del Instituto de Investigación y Estudios de las Ciudades (IN-Ciudades). Universidad de Guadalajara, México. Correo electrónico: cacs2489@hotmail.com / carlos.crespo@ academicos.udg.mx
} 


\section{Introducción}

El Programa de Rescate a Espacios Públicos (PREP a partir de ahora) surge en el 2011, propuesto por parte del gobierno mexicano a través de la Secretaría de Desarrollo Social (SEDESOL), como iniciativa para mejorar la calidad de vida y la seguridad de la población en condición de marginación, en ciudades y zonas metropolitanas del país, mediante la atención de espacios públicos en condición de deterioro, abandono o inseguridad (SEDESOL, 2011).

Este programa lleva 6 años en operación, en este periodo ha sufrido pocos cambios, sin embargo, no por ello poco significativos. Se menciona ahora dos cambios importantes:

El primero se genera sobre el organismo institucional encargado de administrar el programa. En 2011, la SEDESOL genera los diagnósticos pertinentes, estructura y difunde el programa. En el año 2013, tras el cambio de gobierno, surge la Secretaría de Desarrollo Agrario, Territorial y Urbano (SEDATU), la cual toma el mando del programa, y con ello, el programa pasa de tener una raíz social a ser contemplado como un instrumento más para planear y proyectar intervenciones urbanas enfocadas en el desarrollo, sobre todo económico, del territorio.

El segundo cambio, como consecuencia del anterior, es la modificación en el objetivo y la población a la que va dirigido. Como se citó anteriormente, el plan inicial contemplaba como prioridad brindar el apoyo a zonas con mayor índice de marginalidad dentro de la ciudad, sustentando esto en la idea de vincular al desarrollo urbano con el desarrollo social para contribuir a prevenir la inseguridad y la violencia social, tras tomar las riendas del programa SEDATU, el objetivo general del programa se sustenta en contribuir a consolidar ciudades compactas, productivas, competitivas, incluyentes y sustentables, que faciliten la movilidad y eleven la calidad de vida de sus habitantes mediante al rescate de espacios públicos urbanos en condición deterioro, abandono o subutilizados (SEDATU,
2014) y su población objetivo es toda aquella que pertenezca a comunidades urbanas integradas físicamente a zonas metropolitanas. De esta forma, el programa se promueve actualmente dentro de la política pública de consolidación, progreso y, por tanto, competitividad de las ciudades, particularmente, de sus áreas centrales.

Desde su surgimiento y hasta la actualidad, la forma en que el programa se postula como un medio para promover el desarrollo de espacios públicos de "calidad" es a partir de brindar apoyo financiero, proveniente del gobierno federal, para impulsar proyectos generados y promovidos por los gobiernos locales, que aporten al efectivo uso y disfrute de espacios públicos. El apoyo por parte del gobierno federal consiste en asumir el 50\% del costo total del proyecto presentado, mientras que el 50\% restante debe provenir de la administración municipal local, sea total o parcialmente a partir del apoyo conjunto con iniciativa privada.

El apoyo puede emplearse en proyectos estructurados bajo las dos modalidades propuestas por el programa: Mejoramiento físico del espacio, y participación social y seguridad comunitaria.

El mejoramiento físico de los espacios públicos contempla la construcción, la ampliación, el habilitamiento o el rehabilitamiento de espacios públicos destinados a fines recreativos, culturales, turísticos y deportivos. Intervenciones que atiendan a la legibilidad, seguridad, accesibilidad y la movilidad, principalmente (SEDATU, 2014).

Por su parte, las intervenciones relacionadas con la modalidad de participación social y seguridad comunitaria tienen por objetivo: impulsar la organización ciudadana y su participación en la planeación, ejecución y operación de espacios públicos; promover el desarrollo de actividades recreativas, artísticas y culturales, enfocadas a prevenir conductas antisociales de riesgo; e impulsar comités vecinales para garantizar la seguridad (SEDATU, 2014).

Los recursos otorgados contienen una condicionante distributiva, para el mejoramiento físico del espacio se podrá utilizar máximo el 90\% 
del recurso, mientras que para el ejercicio de la modalidad de proyectos de participación social y seguridad comunitaria se destinarán al menos un $10 \%$ de los recursos solicitados.

Dentro de la exposición de esta restricción se hace evidente que el interés predominante para el destino de los recursos se enfoca en su primera modalidad, es decir, en la intervención y mejoramiento de las condiciones del espacio físico, y la segunda, se fija como un complemento secundario.

\section{Elementos desde los que se justifica el proyecto de rescate a espacios públicos}

El sustento o justificación a partir del cual se plantea la necesidad del rescate al espacio público tiene raíz en los resultados del diagnóstico sobre las condiciones de los espacios públicos en México (2010) generado por la SEDESOL, en este documento se describe un espacio público en crisis, abandono y subutilización, en el que fenómenos urbanos como la fragmentación, la privatización y la inseguridad, principalmente, influyen sobre el detrimento en la calidad del espacio público, al menos en tres aspectos: el deterioro y precariedad física del espacio y, por tanto, de la imagen urbana del lugar; la poca oferta de actividades recreativas debido a la incompatibilidad espacial con las necesidades comunitarias, lo que conlleva, según este planteamiento, a la reducción considerable de oportunidades para la interacción social, y, por tanto, limitado interés en formar parte de los procesos de participación ciudadana; y por último, la presencia de conductas de riesgo y por tanto, aumento de la inseguridad en espacios públicos, tanto en cifras objetivas como perceptuales.

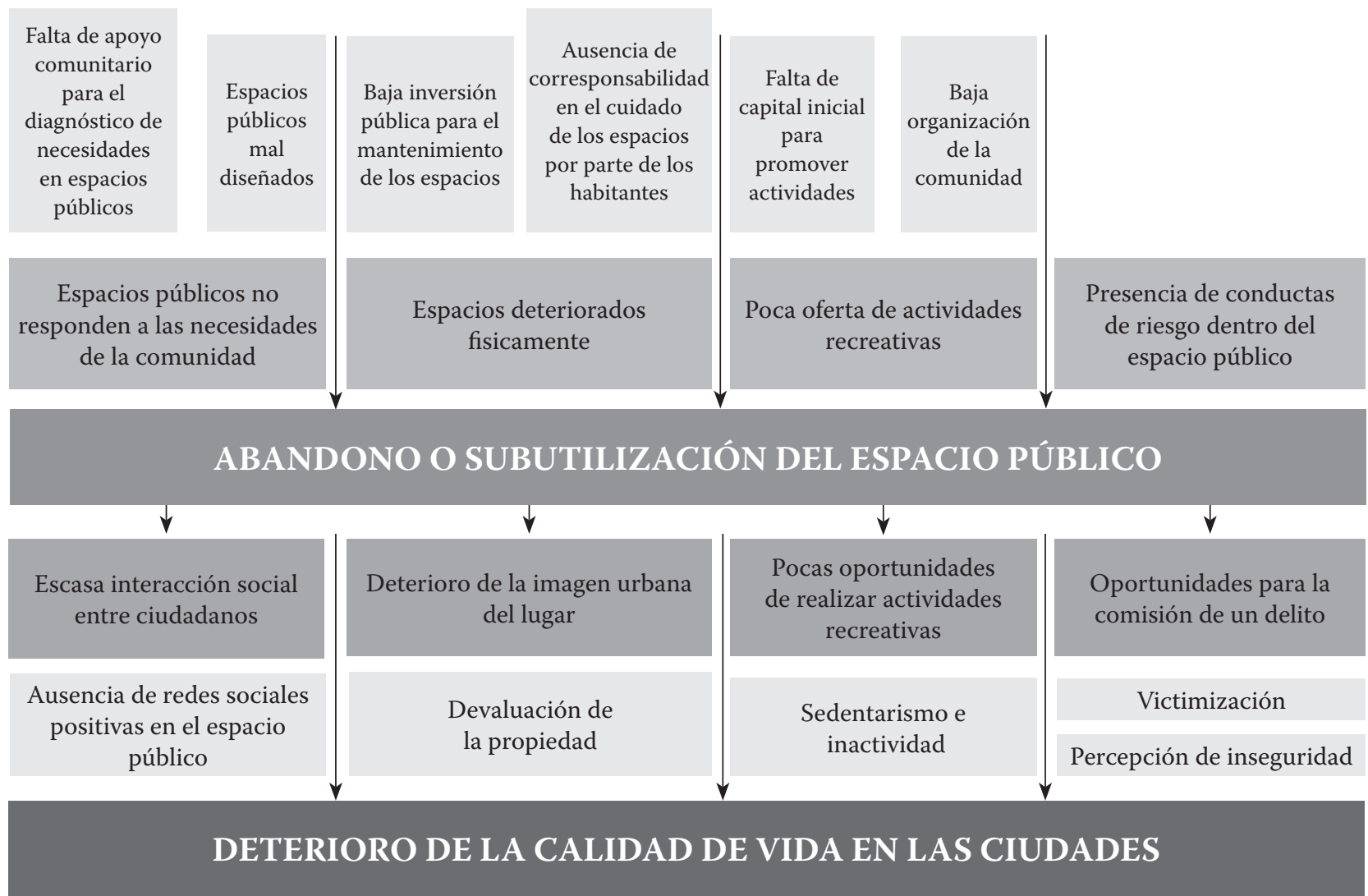

Figura 1. Diagnóstico de problemas detonantes del abandono del espacio público. Fuente de datos: (SEDESOL, 2010) elaboracion propia 
Si bien las problemáticas enlistadas en el diagnostico parecen abarcar diferentes líneas de abordaje, las estrategias y acciones propuestas se sitúan sobre una problemática en concreto, la inseguridad, fenómeno que se difunde como causa principal de los problemas adyacentes que acompañan al abandono del espacio público.

La inseguridad en México es un fenómeno del que gran parte de su población ha sido víctima directa o indirecta, tras ello, es evidente que el sentimiento de inseguridad impere en la ciudad y su espacio público. Según lo plantea Bannister y Fyfe (2001), el miedo y sentimiento de inseguridad tienen tres principales fuentes de alimento: la primera proviene de las experiencias de victimización, sean directas, a partir del sufrimiento de un acto violento, o indirectas si la referencia es ajena; la segunda tiene origen directo en las características físicas del ambiente urbano con el que se interactúa, el individuo carga consigo con ideas preconcebidas al respecto de los elementos estéticos que habilitan este sentimiento de inseguridad; y como última fuente de inseguridad se establece el grado de control individual y social, es decir, la capacidad del individuo de poder tener control sobre su propia vida y, más importante, sobre el comportamiento y las acciones de las demás personas con las que comparte un mismo espacio.

La complejidad que acompaña a cada una de las tres fuentes citadas cuenta con valores amplios para su análisis y la posible instrumentación de medidas para tratar de aminorar este sentimiento de inseguridad, sin embargo, se debe dejar claro, el programa en cuestión resulta reductivo en este aspecto, debido a que ancla sus posibilidades de éxito fundamentalmente sobre la atención directa a las características físicas del ambiente urbano, sin que esta apuesta busque relacionarse con alguna otra política pública complementaria que intente atender las otras dos fuentes de sentimiento de miedo e inseguridad.

Las directrices de intervención espacial que propone el programa se sustentan en el modelo de Prevención de la Delincuencia Mediante el Diseño Ambiental (CPTED, por sus siglas en inglés) propuesto por Jeffery (1977), y cuyo antecedente teórico directo son las reflexiones en torno al Espacio Defendible de Newman (1979). Este modelo busca garantizar la seguridad, controlar las prácticas sociales violentas o actos delictivos, a partir de dos enfoques: la reducción en las oportunidades de la comisión delictiva a partir del diseño espacial, es decir, a partir de disponer del espacio físico para convertirlo en elemento disuasorio; y la disminución de la percepción de inseguridad por medio del fortalecimiento de la cohesión social.

A continuación se analizan críticamente los criterios de intervención arquitectónica y urbana planteados sobre la plataforma material de lo público, eje principal de la estrategia de rescate a espacios públicos en México. Este análisis permitirá reflexionar al respecto de la relación entre la ciudad anhelada y la ciudad negada.

\section{Intervenciones urbanas hacia la ciudad anhelada}

El PREP tiene como uno de los sustentos principales para sus intervenciones, tanto materiales como sociales, a la Guía de Diseño del Espacio Público Seguro, Incluyente y Sustentable (2011), generada por SEDESOL en conjunto con ONU-Hábitat, este documento funge actualmente como base importante para definir los criterios de calidad que el espacio público debe alcanzar para ser definido como "un lugar donde cualquier individuo tiene derecho de entrar y permanecer sin ser excluido por condición personal, social o económica. En parques, plazas, calles y demás espacios públicos los habitantes se encuentran como iguales haciendo uso de un espacio común" (SEDESOL \& ONUHábitat, 2011, p. 33). Para ello, se establecen los parámetros de diseño espacial y social que fundamenta el proyecto de rescate y que aportan, desde la perspectiva institucional, a la garantía de la seguridad, la inclusión y la sustentabilidad del contexto público a partir de su intervención material.

Tanto las reglas de operación del programa, como la guía de diseño espacial citada, plantean la 
posibilidad de rescatar el espacio público a partir de la predominante intervención sobre el diseño espacial, esta perspectiva de abordaje a las problemáticas se justifica dentro de los documentos bajo tres hipótesis principales: la primera plantea que un espacio con características cualitativas deficientes, y por tanto, con limitados atributos estéticos, se convierte en un promotor de actos delictivos y vandálicos; la segunda, que la percepción de inseguridad se encuentra alimentada por la indefinición espacial y por la falta de control sobre los acontecimientos emergentes, azarosos y por tanto inciertos, lo que detona la reclusión social en espacios privados; y la tercera, en consecuencia a las dos anteriores, que la facultad del espacio público como superficie política y de encuentro depende de recuperar la percepción de seguridad entre los habitantes, y para ello, los esfuerzos deben enfocarse en homogeneizar los patrones de diseño, a fin de que por medio del control espacial, se logre controlar al máximo aquellos comportamientos fundados en la incertidumbre y la indefinición.

Para alcanzar el objetivo de generar espacios públicos seguros, incluyentes y sustentables, se establecen dentro de la guía de diseño los siguientes criterios para intervenir físicamente al espacio:

\section{Visibilidad}

Apropiación visual
Se relaciona con las características de las edificaciones como ventanas y balcones y la configuración espacial. Un alto grado de visibilidad colabora con un mayor control de la comunidad sobre su espacio público.

\footnotetext{
Se refiere a observar y ser observado, $y$ depende de si el espacio público permite ver a través de él. La gente domina visualmente el espacio y se da cuenta de opciones que tiene a su alcance; es una característica importante para la percepción de seguridad al procurar la vigilancia natural.
}

Figura 2. Criterios de diseño para el rescate a espacios públicos en México. Fuente de datos: (SEDESOL \& ONUHábitat, 2011). Elaboración propia

Desde el diseño urbano se tiene claro que un espacio público debe poder ser vigilado durante gran parte del día. Se establece que por medio de la vigilancia natural las personas cuentan con una menor probabilidad de ser violentadas, debido a la posible inhibición del acto violento a partir de hacer saber al perpetuador delictivo que se encuentra bajo observación periférica constante, $y$, por otro lado, en caso de perpetuarse el acto, la víctima contará con una mayor oportunidad de ser auxiliada. Bajo este par de atributos se establece que un espacio público de calidad debe fungir como zona de resguardo, zona de vigilancia constante, delimitada por edificios con fachadas frontales activas.

Para contar con un espacio público vigilado constantemente, además de tener una disposición espacial compatible con el fin, es necesario que exista el conocimiento mutuo entre las partes que componen al grupo interno, al grupo vigilante, una red comunicación efectiva entre ellos, o simplemente características afines que los igualen y que haga más sencilla la tarea de reconocer visualmente, por simples estereotipos físicos o de comportamiento, al diferente, a aquella persona que no pertenece el contexto inmediato y que, por el solo hecho de ser extranjero, merece la pena vigilar y estar atento a cada uno de los movimientos que ejecute dentro del contexto inmediato, a fin de alertar al resto de grupo en caso de existir una amenaza de su parte.

Para tener una apropiación y control visual efectivo del espacio público, es necesario contar con lazos comunitarios fuertes que detonen una identidad clara dentro del núcleo social vigilante.

\begin{tabular}{c|l}
\multicolumn{1}{c}{ Lazos } & $\begin{array}{l}\text { Redes de conocimiento y afecto que establecen } \\
\text { los habitantes de una comunidad. Para que } \\
\text { el mecanismo de vigilancia natural funcione } \\
\text { no solo se requiere de un medio ambiente } \\
\text { construido permeable, sino que también una } \\
\text { comunidad esté dispuesta a vigilar y proteger a } \\
\text { sus vecinos. }\end{array}$ \\
Identidad & $\begin{array}{l}\text { Se consideran los elementos que identifiquen a } \\
\text { los vecinos y usuarios con el espacio, de forma } \\
\text { tal que lo sientan propio y puede ser a partir } \\
\text { de su misma participación en el proceso de } \\
\text { intervención. }\end{array}$ \\
\hline
\end{tabular}

Figura 3. Criterios de diseño para el rescate a espacios públicos en México. Fuente de datos: (SEDESOL \& ONUHábitat, 2011). Elaboración propia 
Por medio de estos atributos se establece la necesidad de que el espacio público funja como plataforma de fortalecimiento identitario, en el que sea posible ver enraizados los valores de la Gemeinschaft (comunidad) Tönniesiana (1887) hecha toda ella de solidaridad, lealtad, afectividad, adscripción y consenso, a partir de relaciones sociales guiadas por la búsqueda constante de acuerdos suscritos sobre intereses comunes, comunidad en defensa de lo que los define, la homogeneidad. En este mismo orden, Sennet (1997) manifiesta que es precisamente esta búsqueda de comunidad la que fundamentó el establecimiento de las clases medias altas en suburbios durante el periodo posguerra, la lejanía de todo aquello que pone en riesgo aquel sentido de unión entre iguales $y$, por consecuente, el fortalecimiento de un "tejido social estable" fueron y son actualmente los principales motivos para emprender la huida de lo urbano.

La creación de comunidad por medio del espacio público propone garantizar que, por medio de una vigilancia constante, lo que es de interés común a los miembros no sea puesto en riesgo ante lo artificial, lo pasajero, lo aparente y, por tanto, indefinido de una sociedad hecha toda de heterogeneidad, la Gesellschaft (sociedad) Tönniesiana.

A partir de este criterio, un espacio público de calidad debe dejar clara la frontera entre: el "nosotros", miembros de la comunidad, vigilantes naturales; y "los otros", personajes en tránsito, deambulantes sin arraigo, sin identidad reconocible.

Variedad de usos

Maximizar los usos de acuerdo con la demanda; la manera cómo pueden combinarse y sean compatibles; su factibilidad económica y funcional. Esto contribuye a la oportunidad de que el espacio sea usado por diversos grupos y a distintos horarios; esto promueve los vigilantes naturales en los espacios públicos.

Figura 4. Criterios de diseño para el rescate a espacios públicos en México. Fuente de datos: (SEDESOL \& ONUHábitat, 2011). Elaboración propia
Ahora bien, otro aspecto importante para garantía de calidad es el que todo espacio público tenga totalmente definidos los usos, actividades y periodos de tiempo estipulados para su disfrute.

Por medio de este atributo se busca que las actividades sobre el espacio público se prolonguen en horario, esto a partir de la mixtura entre uso habitacional, comercial, recreativo, entre otros. De tal forma que la presencia prolongada de ojos en la calle haga disminuir la percepción de inseguridad. Para que este atributo sea cumplido desde la espacialidad se requiere claramente de la existencia de "factibilidad económica y funcional" en la zona, por lo que aquellas áreas que no cuentan con las características para ser rentables económicamente a la variabilidad de usos, ya sea por ubicación, por carencia de polos de atracción, o por estigma territorial, deben de buscar las vías para presentar una cara más viable para dichas inversiones.

Otros atributos mencionados en esta guía y que hacen alusión directa a las características específicas con las que debe contar el espacio para que los anteriores atributos cuenten con una plataforma viable para garantizar su efectividad son: el cuidado de la vegetación, una mala elección de las especies o su falta de mantenimiento se puede convertir en un elemento que fomente los delitos de oportunidad debido a la obstrucción del campo visual; la limpieza del espacio, en este atributo se hace referencia a la confianza generada en los vecinos al saber que alguien está a cargo del cuidado del espacio; la iluminación es otro elemento de relevancia en la cualificación espacial, habilita actividades nocturnas en el espacio y se relaciona directamente la vigilancia y el monitoreo constante de las áreas públicas; por último, la señalética, debido a que permite sentirse ubicado, brinda certeza respecto a donde se está y a donde se dirige la persona.

Existe solo un par de atributos que hacen referencia a la relación de la demarcación espacial delimitada y su exterior: la conectividad y la accesibilidad. 


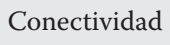

Contar con accesos claros y definidos se refiere a la cantidad y calidad de rutas que llevan al espacio público y la posibilidad de recorrerlo, es decir, a lo externo y a lo interno.

Figura 5. Criterios de diseño para el rescate a espacios públicos en México. Fuente de datos: (SEDESOL \& ONU-Hábitat, 2011). Elaboración propia.

A partir de ellos se hace explicito el interés por enlazar los espacios públicos de calidad dentro de una red a escala ciudad, en la que la vinculación entre uno y otro sea franca y permita el intercambio entre diferentes contextos, cada uno de ellos con lazos comunitarios consolidados.

Como se ha hecho notar en muchos de los criterios expuestos, el interés principal es poder salvaguardar al usuario de experiencias catalogadas como negativas, así, el garantizar una percepción y sensación de seguridad dentro de estos espacios resulta fundamental para el disfrute de los espacios públicos de calidad.

Por su parte, la segunda modalidad del programa: Participación Social y Seguridad Comunitaria, funciona como complemento al mejoramiento físico, se establece a la participación como método para lograr que las modificaciones físicas tengan el efecto previsto, por lo que la inclusión del individuo queda acotada a los procesos de gestión del contexto físico inmediato, esto se evidencia en la conceptualización que aporta la visión institucional al respecto de la participación, definiéndola como el modelo a partir del cual el gobierno facilita a las comunidades la gestión de su entorno, apoyando al descubrimiento de sus propios recursos y en el desarrollo de las soluciones que satisfagan sus propias necesidades, esto, a partir de incentivar la organización hacia la toma de decisiones compartidas (SEDESOL \& ONU-Hábitat, 2011).
Se pretende que, a partir de la participación social, se logre: fortalecer la unión entre gobierno-ciudadanos; generar una sociedad informada y educada; promocionar el bien común como objetivo social y aumentar la conciencia cívica; igualdad de colaboración para los grupos minoritarios; promocionar la tolerancia hacia puntos de vista diferentes y favorecer la pluralidad; y por último, una mayor apropiación ciudadana de los proyectos, defendiéndolos y disminuyendo la presión de los opositores (ONU- Hábitat \& SEDESOL, 2014, p. 159).

Un mecanismo de participación efectivo, bajo el esquema propuesto, se establece bajo dos momentos o etapas: la primera en la que la institución gobierno comparte información con el ciudadano, esperando que este retroalimente al proyecto, a esto se le llama participación en dos vías, en esta etapa se pueden emplear talleres, foros, mesas y brigadas de trabajo comunitario; la segunda consiste en el uso de herramientas específicas para las tomas de decisión, se proponen solamente dos, la consulta ciudadana y el consenso.

Ambas etapas dentro del proceso, aun contando con diferenciadas herramientas, comparten un mismo fin, alcanzar la conjunción de todas las partes, a partir de la creación de reglas internas a las que todo individuo debe alinearse para ser considerado parte del ejercicio, dentro de las principales se encuentra la reducción de la subjetividad, los temas deben ser tratados de manera objetiva entre el grupo individuos, los pensamientos alternos al cause que se establece sobre el tema a tratar deben ser reprimidos por el bien "común", se doblegan las diferencias a fin de hacer prevalecer el interés general, imponiéndose así el consenso como principio moral.

Los formatos propuestos requieren de una delimitación de audiencias, tanto en número como en el grado de compatibilidad respecto a valores compartidos, para ello, se establecen métodos y criterios específicos que permitan seleccionar a los sectores involucrados y a sus representantes, sobre los cuales se posa la confianza de una real 
representatividad, sin que existan los medios para certificar que efectivamente exista una unificación real de perspectivas al interior de las agrupaciones. Otro aspecto importante es que la forma de participación propuesta requiere de ejercer una clara convocatoria, es decir, el individuo que acude a ellos tiene plena conciencia del tema a tratar, la institución convocante, la locación que contendrá al proceso, por lo general, la formulación de la convocatoria define la perspectiva dominante que regirá al acuerdo, en muy pocos casos, la convocatoria se realiza sin una demarcación clara.

Así, los medios de participación promovidos institucionalmente se instauran como un medio acelerador de los procesos de negociación entre las partes que conforman la heterogeneidad social, teniendo como principal objetivo minimizar el conflicto entre ellas, y con ello, hacer prevalecer el acuerdo, difundirlo como interés común y traducirlo inmediatamente a en formas espaciales $\mathrm{y}$ normativas concretas que fungen como ejes rectores y reguladores de las prácticas sociales.

Como se puede observar, desde la perspectiva institucional, la ciudad y el espacio público anhelado se deben componer, en su totalidad, de parámetros y criterios definidos que evoquen seguridad a partir de exponer certezas y, por tanto, reducir incertidumbres, el espacio público se exhibe así como un producto, una plataforma diseñada para garantizar el orden y el control de las prácticas sociales a partir de mecanismos disuasorios, y a partir de la generación de comunidades fuertemente cohesionadas, regidas por intereses comunes, promotoras de buenas prácticas y vigilantes naturales en el cumplimiento de las mismas.

Todo anhelo de cambio, proveniente de un ideal progresista, tiene origen en la existencia de una realidad presente que se considera perfectible, una realidad presente maleable, terreno estable sobre el cual fijar una losa más en el camino hacia una visión utópica. En el caso específico del ideal de cambio que sustenta las aspiraciones sobre el espacio público el terreno no resulta del todo estable, el cambio emerge a partir de una nece- sidad urgente, a partir de la voluntad de rescate de un espacio público en ruinas, en abandono, en crisis.

A continuación, describiremos a ese espacio público que se pretende erradicar, aquel espacio que caracteriza y genera los actuales pensamientos distópicos sobre la ciudad futura.

\section{Ciudad negada, caracterización del mal erradicable}

Considerando los atributos antes descritos y analizados, ahora se hace pertinente tratar de caracterizar la no ciudad, aquel espacio residuo, espacio que carece de los criterios de calidad establecidos por el diseño urbano que son promovidos como garantía de orden y control espacial.

Respecto a su materialización este espacio propenso para el abandono carece de toda lógica estructural nítida, presenta una difícil lectura morfológica, indefinida, indeterminable, sin referencias claras, impredecible, espacio habilitado para promover experiencias emergentes y sorpresivas constantes debido a que se encuentra desprovisto de elementos que hagan predecible las acciones que, "por lógica", deben acompañarlo. Contexto espacial carente de hitos, sendas, bordes, nodos, desprovisto de una imagen legible e interpretable. Abundante en posibilidades para hacer, carente de una delimitación clara de áreas específicas para ejecutar cada acción, sin instructivos.

Espacio provisto para el ocultamiento, con recovecos, con fisuras en donde cualquier cosa puede pasar, espacio de visibilidad exterior limitada.

Un espacio poco legible, y poco visible, solo puede compartir sitio con un contexto inmediato heterogéneo en aspectos formales como escalas, patrones, volúmenes, colores, entre otros, es decir, un paisaje poco homogéneo. Aspecto que, según lo planteado, detona experiencias sensoriales desagradables, un paisaje urbano sin características estéticas admirables solo puede estar condenado a fungir como plataforma de tránsito, sin elementos 
contemplativos, sin atributos para ver, oír, oler, sentir, sin caracteres estéticos.

Por otro lado, desde una perspectiva funcional, otro aspecto que fomenta el abandono espacial es el predominio de suelos circundantes ocupados por actividades únicas, poco diversas, en donde grupos con características comunes pueden apropiarse de lo existente a partir del dominio de usos específicos y únicos.

Por último, en este espacio se carece de control social, de vigilancia constante de lo que en él sucede. Observar y ser observado es la idea central sobre la que se sustenta el aporte, desde el proyecto espacial, al fortalecimiento del sentimiento de seguridad en el espacio público, por lo que el espacio erradicable, al que ahora dedicamos líneas descriptivas, es un espacio que no puede ser vigilado, un espacio cerrado al ojo observador.

De esta afirmación surge un par de preguntas importantes: ¿quién o quiénes vigilan? y ¿a quién o a quiénes se vigila?

Para dar respuesta a estas interrogantes se establece a la identidad como atributo social sin el que la vigilancia espacial se torna imposible. Como ya se ha hecho mención anteriormente, la identidad emerge a partir de lazos comunitarios fuertes entre grupos con intereses arraigados y compartidos, por lo que quien vigila es un sujeto con fuerte arraigo comunitario y a quien se vigila es a su similar, ¿de quién se vigila? de individuo extraño, de aquel que no pertenece por no compartir atributos similares, por no formar parte del núcleo identitario.

Según establece Tönnies, el antagonista del sujeto de identidad comunitaria es aquel individuo que ejerce a partir de relaciones de colectividad, cuya lógica se ampara en la diversidad, relación constante entre individuos que interaccionan libremente teniendo como valor fundamental el respeto a lo que los diferencia, una diversidad no anunciada, solo dada por entendida, la cual hace emerger, por tanto, individuos anónimos. Este anonimato ejercido sobre el espacio público, según se plantea, resulta ser un detonante más del sentimiento de inseguridad.

Así la identidad es concebida como un aspecto positivo y la indefinición de características sociales compartidas como un aspecto negativo. En ello recae una contradicción importante, se establece con anterioridad que uno de los aspectos espaciales negativos es la ocupación predominante de usos específicos y únicos dentro del contexto, esto, según se argumentaba, abre espacio a la apropiación por parte de un solo grupo de dominio, sin embargo, ahora se habla de la necesidad de generar lazos comunitarios que se unifiquen a partir del sentimiento de identidad y que estos marquen la pauta del orden espacial a partir de la procuración del cumplimiento de los valores compartidos a partir de la vigilancia constante.

¿Quién vigila? un sujeto identificado con la lógica predominante del lugar, ¿a quién vigila? a su similar, ¿de quién lo vigila? del individuo anónimo, aquel que le es otorgado el gafete de extranjero por el solo hecho de no ser reconocido.

Ilegible, indeterminado, indefinido, oculto, con bajo grado de visibilidad, casi imposible de vigilar, carente de elementos estéticos contemplables, sin variedad de usos y actividades, inapropiado socialmente, carente de elementos simbólicos identitarios, de esta forma se describe al espacio público carente de calidad, según los parámetros de medición que se expone como política pública de atención y rescate en México.

Son estos parámetros óptimos de diseño espacial del espacio público los que se difunden y a partir de los cuales se busca que la población de una ciudad sepa diferenciar los espacios públicos factibles para el ocio, la contemplación, la recreación, para el encuentro e intercambio social, la política, de aquellos otros a los que no se le puede adjuntar valor estético, recreativo, de encuentro democrático, aquellos otros que alejan al individuo de formar parte del nosotros, un nosotros que permite pertenecer a los que los cánones promulgan como normal. 


\section{Entre la negación y el anhelo surgen las incongruencias}

Tras analizar los elementos a partir de los cuales se justifica el proyecto de rescate a espacios públicos, y tras describir y analizar críticamente, tanto los parámetros que definen la representación aspiracional de cambio como los que sustentan al mal erradicable desde el que emerge la urgencia de intervención, se hace necesario exponer algunos aspectos que vuelven incongruente el planteamiento de rescate al espacio público bajo los parámetros establecidos en el PREP.

Comenzaremos por algo elemental, el objetivo manifiesto de rescate del espacio público.

Se parte de un argumento manifiesto de preocupación y sentimiento nostálgico de pérdida del espacios público debido a que este se presenta actualmente como el contenedor de problemáticas diversas, se afirma así que "alguna vez existió un espacio público desproblematizado", un espacio urbano comunitario, igualitario, equitativo, de relaciones sanas y puentes sólidos de diálogo entre sociedad y Estado, un espacio sin distinción de clases, en donde la cultura de las permanencias se anteponía a lo efímero, en donde el tiempo para la recreación y el ocio eran bastos, en donde reinaba la seguridad porque no había espacios para que un individuo se sintiera violentado, en donde todos participaban de la vida política y social, en donde todas las áreas de la ciudad se encontraban en conexión absoluta y accesibles para la totalidad, en donde los espacios de la ciudad contaban con altos índices de calidad, etc. ${ }^{1}$

La palabra "rescatar" desde su origen etimológico proviene del latín recaptare compuesto por el prefijo "re" en su función de atracción al presente un evento, situación, o función ejecutada en el pasado y que por alguna razón ha dejado de ser,

1 Para informarse más al respecto del origen de dichas aseveraciones nostálgicas de la existencia de un espacio público idealizado se aconseja leer: Delgado (1999), Sennet (1977) y (1997), y Salcedo Hansen (2002). y del verbo capere que significa coger, tomar o capturar (Real Academia Española, 2014). Tras su definición es pertinente preguntarse, en realidad ¿alguna vez existo este espacio ideal evocable?, si la respuesta es afirmativa sería pertinente exponer el grado de compatibilidad entre los valores pasados del espacio público que se desean retomar y la dinámica que estructura a la sociedad contemporánea. Por otro lado, si la respuesta es negativa, el rescate como objetivo carece de todo fundamento.

Prescindiendo de la respuesta a la interrogante que antecede, como lo hemos visto, este proyecto de "rescate" ya cuenta con parámetros espaciales y conductuales definidos, estos responden a cánones estéticos y normativos específicos que emergen de un grupo social imaginario que se caracteriza como igualitario, es decir, despojado de todo posible fenómeno de desigualdad que desafíe estos valores democráticos (Delgado, 2011). Se reconoce en los criterios de validación hacia el recate del espacio público algunos atributos que con anterioridad se percibían distintivos de aquellos "espacios semipúblicos privados" a los que se les denominó a partir de los años 90, sobre todo, como uno de los principales motivos del abandono de los parques, las plazas y las calles, criticándolos por ser contenedores de ocio y recreación regidos por una clase social predominante que definía usos y comportamientos normativizados. Los malls, centros comerciales, los parques temáticos, y demás tipologías de espacios semi-públicos que se satanizaban ayer, hoy parecen ser las perfectas incubadoras de ideas para el rescate de lo público.

Parecería que la crítica se endurece sin una problemática sólida de trasfondo, ¿qué de malo hay en que se procuren estos archipiélagos de calidad espacial dentro de las ciudades? Proponemos ahora reflexiones al respecto.

En países en vías de desarrollo, en donde existe un alto grado de desigualdad, como es el caso de México $^{2}$, diferenciar espacios públicos de calidad

2 País en donde dos terceras partes del total del capital se concentra en apenas el $10 \%$ de la población, un país con un 
frente a espacios públicos carentes de esta fomenta una exacerbación de las diferencias en las capacidades y las plataformas para el desarrollo y calidad de vida de las personas. Estas diferencias no solo repercuten en el grado de apropiación espacial e identificación simbólica con el lugar en donde se radica, considerando que el espacio público se autodenomina como plataforma de contacto e intercambio cultural, social y político, la carencia de estos repercutirá también en el grado de representación y de influencia sobre los ejercicios políticos determinantes de la dinámica de ciudad, en otras palabras, esta división hace que para el Estado y para algunos sectores sociales, así como existen espacios sin calidad, espacios residuales, existen también individuos residuales, es decir, sin la calidad suficiente para ser catalogados como ciudadanía. Esto representa una clara contradicción en las aspiraciones sociales de igualdad, un atentado hacia el espíritu democrático que se promueve y se difunde discursivamente a partir de la institución de la ciudad.

Queda claro que esta diferenciación espacial conlleva también una diferenciación social desde la que se etiqueta a una sociedad o colectividad como de segundo nivel, esta diferenciación fragmenta, segmenta y estigmatiza aún más la ciudad a partir de lo que parecería un sencillo gesto progresista.

\section{Reflexiones finales}

La problematización y la propuesta de solución aportada por la institución a los fenómenos urbanos expresados en lo público resulta sumamente reduccionista, fijar una estrategia de "rescate" a la espacialidad pública sobre parámetros de prevención situacional a partir del diseño contextual claramente resulta fuera de contexto. Aspectos como la desigualdad social y por consiguiente la segmentación en clases sociales, la falta de garantía sobre el derecho individual a la segu-

coeficiente de Gini superior al 0.45 respecto a desigualdad de ingreso, y superior al 0.78 en concentración de riqueza. ridad humana (económica, alimentaria, ambiental, personal, de lazos colectivos y política) en la gran mayoría de la población urbana, la voraz especulación de suelo, la venta ilegal de reservas urbanas, la falta de confianza sobre la procuración de justicia, el dominio de la cultura de consumo, las condiciones laborales inhumanas en las que existe un claro control sobre el tiempo de vida de los trabajadores, la falta de coordinación pública y privada, la desconexión urbana, los estigmas sociales y por tanto la discriminación, entre muchos otros aspectos, simplemente desaparecen del diagnóstico, las estrategias y las acciones planteadas sobre lo público.

Es evidente que este programa se enfoca en tratar de atender consecuencias, ignorando, fundamentalmente a partir del fomento de políticas sectorizadas y poco integrales, el sin fin de factores que dan origen al desapego social hacia lo que se hace llamar "espacio público".

En un entorno tan desigual como lo es el territorio mexicano, una política pública en donde las formas, las escalas, los atributos estéticos, los usos, las costumbres, los comportamientos que rigen a la gran minoría se establezcan como atributos modelo y representaciones del bien común anhelado, denota un claro desinterés, más que un desconocimiento, de los organismos institucionales por las causas y las consecuencias reales de la gran brecha que fragmenta territorial y socialmente, aquella brecha de divide al nosotros de los otros, los ciudadanos de los incívicos, entre los espacios públicos de calidad y los espacios residuales, abandonados y de baja calidad, entre los grupos que promulgan la participación por consenso y los que participan practicando el disenso como motor de la constante construcción conjunta de la vida cotidiana.

En este artículo reflexivo se ha decidido analizar solo las posturas institucionales que cuentan con un respaldo estructural expuesto y documentado, aquellos elementos que fungen como amparo institucional, sin embargo, estamos conscientes, y en esta conciencia radica el compromiso de conti- 
nuidad reflexiva, de que en un país como México el poder se ejerce diariamente en la calle, teniendo a lo escrito como justificante para la ejecución arbitraria de mecanismos represivos, en la mayoría de los casos violentos, contra el mal erradicable, contra los despojables, contra grupos y prácticas concretas que, para el sector minoritario -el de las clases medias altas-, representan un freno importante para el progreso, para las aspiraciones y los anhelos de una nación y una sociedad que pretende dejar atrás la etiqueta de "país en vías de desarrollo" y exponerse al mundo, aunque sea a partir de una escenografía simulada, como un país desarrollado.

\section{Referencias bibliográficas}

Bannister, J., \& Fyfe, N. (2001). Introduction: Fear and the City. Urban Studies, 38(5), 807-813.

Delgado, M. (1999). El animal público. Barcelona: Anagrama.

Delgado, M. (2011). El espacio público como ideología. Madrid: Catarata.

Jeffrey, C. (1977). Crime Prevention Through Environmental Design. Beverly Hills: Sage Publications .

Newman, O. (1979). Community of Interest. Nueva york: Doubleday.
ONU- Hábitat \& SEDESOL. (2014). Guía de Diseño del Espacio Público Seguro, Incluyente y Sustentable. Ciudad de México.

Salcedo Hansen, R. (2002). El espacio público en el debate actual. Reflexion critica sobre el urbanismo postmoderno. Eure, 28(84).

SEDATU. (2014). Reglas de Operación del Programa Rescate de Espacios Públicos, para el ejercicio fiscal 2015 y subsecuentes. DOF: 30/12/2014. Secretaría de Desarrollo Agrario, Territorial y Urbano, Ciudad de Mexico.

SEDESOL \& ONU-Hábitat. (2011). Guía de Diseño del Espacio Público Seguro, Incluyente y Sustentable. Ciudad de México.

SEDESOL. (2010). Documento Diagnóstico de Rescate a Espacios Públicos.

SEDESOL. (2011). Reglas de Operación del Programa de Rescate de Espacios Públicos, para el ejercicio fiscal 2012. DOF: 27/12/2011. Secretaría de Desarrollo Social, Ciudad de México.

Sennet, R. (1997). Carne y piedra. El cuerpo y la ciudad en la civilización occidental. Madrid: Alianza.

Tönnies, F. (1887). Community and Civil Society. (J. Harris, Ed.) Cambridge, UK: Cambridge University Press. 